\title{
Supine versus prone PCNL: the debate continues...
}

\author{
Darren Beiko, MD, FRCSC
}

Associate Professor, Department of Urology, Queen's University, Kingston, ON

See related article on page 261.

Cite as: Can Urol Assoc J 2011;5(4):266-7; D0l:10.5489/cuaj.11142

I $\mathrm{s}$ the supine position superior to the prone position for percutaneous nephrolithotomy (PCNL)? Although the study design of the article published in this month's CUAJ did not allow this question to be answered, the researchers did demonstrate that supine PCNL (sPCNL) is safe and effective in their hands. ${ }^{1}$ They achieved a $92 \%$ stone-free rate in their 159 procedures, with only 2 failed renal punctures, 1 blood transfusion and 1 death due to septic shock (i.e., not related to position). No procedures had to be converted to the prone position.

The prone position has been the traditional and most widely used position since PCNL emerged in the mid1970s. The authors propose several potential advantages of the supine position for PCNL, many of which highlight problems or limitations of prone PCNL. Proposed anesthetic advantages include decreased cardiovascular and respiratory disturbances. Proposed surgical advantages include straightforward renal puncture, spontaneous evacuation of stone fragments facilitated by horizontal sheath position and hand of surgeon is outside the field of radiation. Proposed technical advantages include uncomplicated patient positioning, less manipulation of patient under anesthesia and decreased operating room (OR) time.

Based on study design alone it was not possible for the authors to prove any of their proposed advantages of sPCNL. To their credit, the authors fully acknowledged that the major limitation of this project was the study design and the fact it was not a prospective randomized controlled trial (RCT) comparing supine and prone PCNL.

Two very recent meta-analyses comparing supine versus prone positioning for PCNL have been published, ${ }^{2,3}$ both of which were based on 4 publications that met their inclusion criteria - 2 prospective RCTs and 2 case control studies. To date, these are the only 2 prospective RCTs comparing supine and prone positioning for PCNL., ${ }^{4,5}$ Unfortunately, neither RCT randomized more than 40 patients to either arm of the trial. Both meta-analyses concluded that the two positions showed equivalency for stone-free rates and complication rates..$^{2,3}$ Additionally, both found SPCNL resulted in shorter OR times. Furthermore, in last month's Journal of Urology, Duty and colleagues published a comprehensive review on the debate of positioning for PCNL. ${ }^{6}$ According to this review, advantages of SPCNL over prone PCNL included a greater cardiac index, decreased risk of colon injury during lower pole access, decreased radiation exposure to surgeon, improved spontaneous stone drainage through sheath and shorter OR time. Disadvantages of SPCNL included an increased risk of injury to liver and spleen during upper pole access and decreased surface area for percutaneous access. The conclusion in their abstract says it all: "Each position is feasible but more randomized studies are needed to accurately determine the relative efficacy and morbidity of the two positions." This statement accurately reflects my conclusion that PCNL is a safe and effective approach that is an important addition to the armamentarium of any endourologist, but the bottom line remains that we need larger and adequately powered RCTs to determine which PCNL position is superior.

Finally, any discussion about PCNL positioning would be incomplete without mentioning one additional position for PCNL that has been pioneered here in Canada by Dr. John Honey and Dr. Ken Pace - the prone-flexed position. ${ }^{78}$ This position results in improved upper pole access and increased mobility for lower pole access according to their initial study by Ray and associates involving computed tomography scan anatomical surveys in the supine, prone and prone-flexed positions. ${ }^{7}$ Honey and colleagues verified their preliminary findings in their recently published retrospective review of 318 consecutive patients undergoing prone-flexed PCNL 
over a 5-year period. ${ }^{8}$ They concluded that the prone-flexed position for PCNL is safe and effective.

Until a large prospective RCT demonstrates superiority of one position over the others, let the "supine versus prone versus prone-flexed PCNL" debate continue...

Competing interests: None declared.

This paper has been peer-reviewed.

\section{References}

1. El Harrech Y, Ghoundale 0, Zaini R, et al. La NLPC en décubitus dorsal modifié : notre experience. Can Urol Assoc J 2011;5;261-5; D01:10.5489/cuaj.10168.

2. Wu P, Wang L, Wang K. Supine versus prone position in percutaneous nephrolithotomy for kidney calculi: a meta-analysis. Int Urol Nephrol 2011;43:67-77.
3. Liu L, Zheng $S, X \cup Y$, et al. Systematic review and meta-analysis of percutaneous nephrolithotomy for patients in the supine versus prone position. J Endourol 2010;24:1941-6.

4. Falahatkar S, Moghaddam AA, Salehi M, et al. Complete supine percutaneous nephrolithotripsy comparison with the prone standard technique. J Endourol 2008;22:2513-7.

5. De Sio M, Autorino R, Quarto G, et al. Modified supine versus prone position in percutaneous nephrolithotomy for renal stones treatable with a single percutaneous access: a prospective randomized trial. Eur Urol 2008:54:196-202.

6. Duty B, Okhunov Z, Smith A, et al. The debate over percutaneous nephrolithotomy positioning: a comprehensive review. J Urol 2011;186:20-5.

7. Ray AA, Chung DG, Honey RJ. Percutaneous nephrolithotomy in the prone and prone-flexed positions: anatomic considerations. J Endourol 2009;23:1607-14.

8. Honey RJ, Wiesenthal JD, Ghiculete D, et al. Comparison of supracostal versus infracostal percutaneous nephrolithotomy using the novel prone-flexed patient position. J Endourol 2011;25:947-54.

Correspondence: Dr. Darren Beiko, Department of Urology, Queen's University, Kingston General Hospital, 76 Stuart St., Kingston, ON K7L 2V7; fax: 613-545-1970; beiko@queensu.ca 